\title{
Genome-wide association analysis to identify genotype $\times$ environment interaction for milk protein yield and level of somatic cell score as environmental descriptors in German Holsteins
}

\author{
M. Streit, ${ }^{*}$ F. Reinhardt, $†$ G. Thaller, $\ddagger$ and J. Bennewitz ${ }^{* 1}$ \\ *Institute of Animal Husbandry and Breeding, University of Hohenheim, 70599 Stuttgart, Germany \\ †Vereinigte Informationssysteme Tierhaltung w.V. (VIT), 27283 Verden, Germany \\ ¥Institute of Animal Breeding and Husbandry, Christian-Albrechts-University, 24098 Kiel, Germany
}

\section{ABSTRACT}

Genotype by environment interaction $(\mathrm{G} \times \mathrm{E})$ has been widely reported in dairy cattle. If the environment can be measured on a continuous scale, reaction norms can be applied to study $\mathrm{G} \times \mathrm{E}$. The average herd milk production level has frequently been used as an environmental descriptor because it is influenced by the level of feeding or the feeding regimen. Another important environmental factor is the level of udder health and hygiene, for which the average herd somatic cell count might be a descriptor. In the present study, we conducted a genome-wide association analysis to identify single nucleotide polymorphisms (SNP) that affect intercept and slope of milk protein yield reaction norms when using the average herd test-day solution for somatic cell score as an environmental descriptor. Sire estimates for intercept and slope of the reaction norms were calculated from around 12 million daughter records, using linear reaction norm models. Sires were genotyped for $\sim 54,000$ SNP. The sire estimates were used as observations in the association analysis, using 1,797 sires. Significant SNP were confirmed in an independent validation set consisting of 500 sires. A known major gene affecting protein yield was included as a covariable in the statistical model. Sixty (21) SNP were confirmed for intercept with $P \leq 0.01(P \leq 0.001)$ in the validation set, and 28 and 11 SNP, respectively, were confirmed for slope. Most but not all SNP affecting slope also affected intercept. Comparison with an earlier study revealed that SNP affecting slope were, in general, also significant for slope when the environment was modeled by the average herd milk production level, although the two environmental descriptors were poorly correlated.

Key words: genotype $\times$ environment interaction, somatic cell score, association analysis, reaction norm

Received June 13, 2013

Accepted July 27, 2013

${ }^{1}$ Corresponding author: j.bennewitz@uni-hohenheim.de

\section{INTRODUCTION}

The term genotype $\times$ environment interaction $(\mathbf{G} \times \mathbf{E})$ refers to differences in response of genotypes to changes in the environment (Lynch and Walsh, 1998). The environment in which dairy farming is practiced varies considerably, and consequently $\mathrm{G} \times \mathrm{E}$ has been investigated in several studies (e.g., König et al., 2005; Strandberg et al., 2009, and references therein). If the environment can be measured on a continuous scale, reaction norm models are often used to study $\mathrm{G} \times \mathrm{E}$ (e.g., Kolmodin et al., 2002; Hayes et al., 2003; Strandberg et al., 2009). In a reaction norm model, phenotype is modeled as a function of the environment in which the phenotype is produced. The slope of the reaction norm is a measure of the environmental sensitivity. Individuals with steep (flat) slope are called environment-sensitive (robust) individuals. A nonzero variance of the slope indicates the presence of $\mathrm{G} \times \mathrm{E}$.

The choice of an appropriate environmental descriptor is of fundamental importance. Frequently, the average herd production level of the trait under consideration is used as an environmental descriptor, because it combines many unobservable environmental factors affecting phenotype. In addition, this can be estimated with high precision for many dairy herds, provided that herd size is not too small. Probably the most important environmental factor is the level of feeding, which is captured by affecting average herd milk production (Hayes et al., 2003).

Another important environmental factor for dairy cattle is the level of hygiene and udder health. This is not recorded routinely in Germany, although there is a trend toward implementing special recording schemes on contract herds. However, the level of SCC is routinely collected on many dairy farms for management and breeding purposes. Barkema et al. (1999) and (in a recent review) Dufour et al. (2011) pointed out significant relationships of udder health management practice and herd SCC. Because SCS is included in the panel of traits for which routinely genetic evaluations 
are performed in Germany, reliable average herd SCS levels are available that could be used as environmental descriptor in $\mathrm{G} \times \mathrm{E}$ analysis.

Considering environmental sensitivity or, equivalently, robustness is an increasing issue in dairy cattle breeding (Veerkamp et al., 2009; Hayes et al., 2009). One way to do this is to apply marker-assisted or genomic selection. In both breeding schemes, some knowledge of the genes affecting environmental sensitivity is needed. Therefore, Lillehammer et al. (2009a) and Hayes et al. (2009) extended classical genome-wide association analysis (GWAS) toward considering $\mathrm{G} \times \mathrm{E}$ effects. They estimated for each SNP an effect for intercept and for slope and found environment-sensitive and environment-robust SNP. The latter were significant for intercept but not for slope. In addition, Lillehammer et al. (2009a) mapped a greater number of QTL if $\mathrm{G} \times \mathrm{E}$ was taken into account. Hence, although the model becomes more complex and additional parameters have to be estimated, considering $\mathrm{G} \times \mathrm{E}$ might result in an increase in statistical power to map QTL.

In a previous study, we applied higher-order reaction norm random regression models and found highly significant $\mathrm{G} \times \mathrm{E}$ effects in German Holsteins for the environmental descriptors average herd milk production level and average herd SCS. The analyses were done for each descriptor separately (Streit et al., 2012). The descriptors were slightly negatively correlated $(-0.18)$. In a subsequent study, we conducted a GWAS to identify SNP for milk production traits affecting slope and intercept of the reaction norms in German Holsteins (Streit et al., 2013). We used the average herd milk energy yield as a continuous environmental descriptor. Numerous SNP could be identified that were significantly associated with intercept and slope.

The aim of the present study was to conduct a largescale GWAS for milk protein yield with average herd SCS as an environmental descriptor. We applied a 3 -step procedure. In the first step, estimates for intercept and slope of sire reaction norms were calculated using first-order random regression sire models. These estimates were used in a second step as observations in an association analysis. In the third step, significant SNP associations were confirmed in an independent validation set of the same population.

\section{MATERIALS AND METHODS}

\section{Data and Data Editing}

In total, 2,356 progeny-tested German Holstein sires were genotyped with the Illumina BovineSNP50 BeadChip (Illumina Inc., San Diego, CA; Matukumalli et al., 2009). The sires were born between 1983 and
2003. Data filtering was done using PLINK (Purcell et al., 2007) using the following criteria. Individuals with more than $10 \%$ missing marker genotypes were removed (59 individuals). A SNP was excluded if it had a minor allele frequency $<3 \%$, a call rate $<90 \%$, a significant deviation from the Hardy-Weinberg-equilibrium $(P<$ 0.001 ), or if the position on the genome was unknown; SNP on the sex chromosomes were also excluded. A total of 41,349 SNP remained in the data set. Sporadic missing genotypes were imputed using fastPHASE (Scheet and Stephens, 2006). The average linkage disequilibrium $\left(\mathrm{r}^{2}\right)$ between pairwise SNP at distances of $<25 \mathrm{~kb}$ was 0.3 (Qanbari et al., 2010).

Around 12 million first-lactation test-day records for milk protein yield from daughters of the sires were used. The number of daughters per bull ranged from 50 to 74,842 and totaled around 1.3 million. Test-day records were corrected for the fixed effects herd-test-day, DIM, age at calving, and calving season, and the random permanent environment effect. These correction factors were obtained from the routine animal genetic evaluation. Only daughters with at least 7 observations per year were considered. The environmental descriptors were herd-test-day solutions for SCS, which was obtained from the routine animal evaluation. Observations in extreme and rare environments were discarded (around $2 \%$ of the observations). These restrictions ensured that there were enough observations and variation of the environmental descriptor to apply reaction norms within individual cows and that the results were not affected by (unreliable) extreme and rare environments. The environmental descriptor was rescaled to have a mean of 0 and a standard deviation of 1 .

\section{Statistical Analysis}

The following reaction norm random regression model was applied in the first step:

$$
\begin{aligned}
c y_{i j k}= & \mu+b \times h t d s s c s_{k}+\sum_{m=0}^{1} s_{j m} \times h t d s s c s_{k}^{m} \\
& +\sum_{m=0}^{1} d_{i j m} \times h t d s s c s_{k}^{m}+e_{i j k},
\end{aligned}
$$

where $c y_{i j k}$ is the corrected protein yield of daughter $i$ of sire $j$ at herd-test-day $k, \mu$ is the overall mean, $h t d s s c s_{k}$ is the herd-test-day solution for SCS at herd-test-day $k$ with the fixed regression coefficient $b, s_{j m}$ is the random sire effect of sire $j$ of order $m, d_{i j m}$ the random daughter effect of daughter $i$ of sire $j$ of order $m$, and $e$ is the random residual. The covariance structure of the sire (s) regression effects is 


$$
\operatorname{Var}\left[\begin{array}{l}
s_{0} \\
s_{1}
\end{array}\right]=\mathbf{A} \otimes\left[\begin{array}{ll}
\sigma_{s_{0}}^{2} & \sigma_{s_{0} s_{1}} \\
\sigma_{s_{0} s_{1}} & \sigma_{s_{1}}^{2}
\end{array}\right],
$$

and of the daughter (d) effects is

$$
\operatorname{Var}\left[\begin{array}{l}
d_{0} \\
d_{1}
\end{array}\right]=\mathbf{I} \otimes\left[\begin{array}{ll}
\sigma_{d_{0}}^{2} & \sigma_{d_{0} d_{1}} \\
\sigma_{d_{0} d_{1}} & \sigma_{d_{1}}^{2}
\end{array}\right],
$$

with A (I) being the numerator relationship (identity) matrix. The uncorrelated daughter effects reduce the heterogeneity of residual variance if $\mathrm{G} \times \mathrm{E}$ effects are present (Lillehammer et al., 2009b). The model was fitted using ASReml 3.0 (Gilmour et al., 2009). The estimated sire effects for slope and intercept of the protein yield reaction norms (estimated in model [1]) were treated as 2 different traits and were used as observations in the association analysis (model [2]).

The whole data set was randomly split into a discovery data set ( $\mathrm{n}=1,797$ bulls) and a validation data set $(\mathrm{n}=500 \mathrm{bulls})$. In the second step of the statistical analysis, we performed GWAS using the discovery data set. It is known that DGAT1 segregates in this population and shows a substantial effect for protein yield (Thaller et al., 2003). The DGAT1 K232A substitution is not included in the Illumina BovineSNP50 BeadChip, but the SNP ARS-BFGL-NGS-4939 is in almost complete linkage disequilibrium with this substitution in German Holsteins $\left(\mathrm{r}^{2}=0.998\right.$; Wang et al., 2012). Therefore, we included this marker as a covariate in the statistical model for the association analysis. The following mixed linear model was applied for each marker in turn:

$$
\hat{s}_{j t}=\mu_{t}+b_{t} \times z_{j}+\operatorname{sire}_{j t}+b_{k t} \times x_{j k}+e_{j t},
$$

where $\hat{s}_{j t}$ is the estimated effect of sire $j$ for trait $t$ ( $t$ being intercept and slope, respectively). The term $z_{j}$ denotes the number of copies of the allele with the higher frequency of SNP ARS-BFGL-NGS-4939 observed for sire $j(z=0,1$, or 2$)$, and $b_{t}$ is the regression coefficient. The effect of each SNP $k$ was modeled similarly as a regression on the number of copies of the allele with the higher frequency $(x=0,1$, or 2$)$, with $b_{k t}$ being the regression coefficient. To control the population structure, we fitted a random sire effect with the covariance structure $\mathbf{A} \sigma_{s t}^{2}$, where $\sigma_{s t}^{2}$ is the variance attributable to the sires. This model was applied for each SNP $k$ in turn, resulting in 41,348 association tests per trait. We declared each SNP with a pointwise error probability below $P<0.001$ as significant. To judge how many false positives were among the significant associations, we applied the false discovery rate (FDR) technique. We calculated for each association test an FDR $q$-value using the software QVALUE (Storey and Tibshirani, 2003). The FDR $q$-value of the significant SNP with the lowest test statistic $(P \approx 0.001)$ provided an estimate of the proportion of false positives among the significant associations.

In the third step, we confirmed significant SNP associations within the same population in the validation set. The same statistical model was applied, but only to significant SNP. We declared a SNP as confirmed if the $P$-value in the validation set was either $P<0.001$ (stringent) or $P<0.01$ (less stringent significance level) and the signs of the effects were the same in both sets. The less stringent significance criterion was included because less multiple testing was performed, and the stringent significance level would reduce the power to confirm SNP. A similar strategy was applied by Pryce et al. (2010).

\section{RESULTS}

The estimated variance components $\left(\sigma^{2}\right)$ and correlations $(\rho)$ were as follows: $\hat{\sigma}_{s_{0}}^{2}=848.8(25.77), \hat{\sigma}_{s_{1}}^{2}=1.04$ (0.16), $\hat{\sigma}_{s_{0} s_{1}}=-11.75(1.76), \hat{\rho}_{s_{0} s_{1}}=-0.4, \hat{\sigma}_{d_{0}}^{2}=1,746.38$ (2.95), $\hat{\sigma}_{d_{1}}^{2}=25.36(1.22), \hat{\sigma}_{d_{0} d_{1}}=-43.10(1.26), \hat{\rho}_{d_{0} d_{1}}=$ -0.2 , and $\hat{\sigma}_{e}^{2}=5,167.07(2.28)$. The daughter variance components were larger than the sire variance components. No heterogeneity of the residual variance was observed (not shown). The standard errors (in parentheses) were small for all estimated components. The correlation between intercept and slope was negative for both the sire and the daughter. Table 1 summarizes the results from the association analysis. The FDR analysis revealed that around $8 \%$ of the significant associations were false positives for intercept. Fewer SNP were significant for slope and the FDR was slightly higher. As expected, for both traits, around $60 \%$ fewer SNP could be confirmed using the stringent validation compared with the less stringent validation.

The plots of the test statistic along the chromosomes are shown in Figure 1. Chromosomal positions of validated SNP (less stringent validation) are indicated by triangles. Significant SNP were found on many chromosomes. The highest significance was observed for all 3 traits for the SNP being in near-complete linkage disequilibrium with the DGAT1 K232A substitution on BTA14. No other SNP on this chromosome was significant. Promising SNP clusters affecting intercept were identified on BTA1, 6, 7, 9, 13, 16, 18, 26, and 28. Not all clusters were also significant for slope; see, for example, the SNP clusters on BTA6, BTA13, and BTA16. 
Table 1. Number of discovered and validated SNP (stringent and less stringent validation, $P \leq 0.001$ and $P$ $\leq 0.01$, respectively) for intercept (protein yield) and slope (protein yield)

\begin{tabular}{lcccc}
\hline & & & \multicolumn{2}{c}{ Validation data set } \\
\cline { 4 - 5 } Trait & $\begin{array}{c}\text { Discovery data set } \\
(P \leq 0.001)\end{array}$ & $\mathrm{FDR}^{1}$ & $(P \leq 0.01)$ & $(P \leq 0.001)$ \\
\hline Intercept (protein yield) & 407 & 0.08 & 60 & 21 \\
Slope (protein yield) & 261 & 0.12 & 28 & 11
\end{tabular}

${ }^{1}$ The false discovery rate $q$-values $(\mathrm{FDR})$ of the significant SNP with the largest error probability $(P \approx 0.001)$ in the discovery data set are shown.

The SNP that could be validated (stringent validation) for at least one trait are shown in Table 2. The signs of the effects were in the opposite direction for slope and intercept. Again, not all SNP affecting intercept were also significant for slope. In contrast, some SNP on BTA11, 16, 18, and 21 were validated for slope but not significant for intercept. These SNP would have been missed without modeling $\mathrm{G} \times \mathrm{E}$ in the analysis. All SNP that could be validated for at least one trait (less stringent validation) are shown in Supplemental Table S1 (available online at http://dx.doi.org/10.3168/ jds.2013-7133).

\section{DISCUSSION}

In the present study, numerous SNP were identified that affected intercept and slope of sire protein reaction norms when the environment was modeled as average
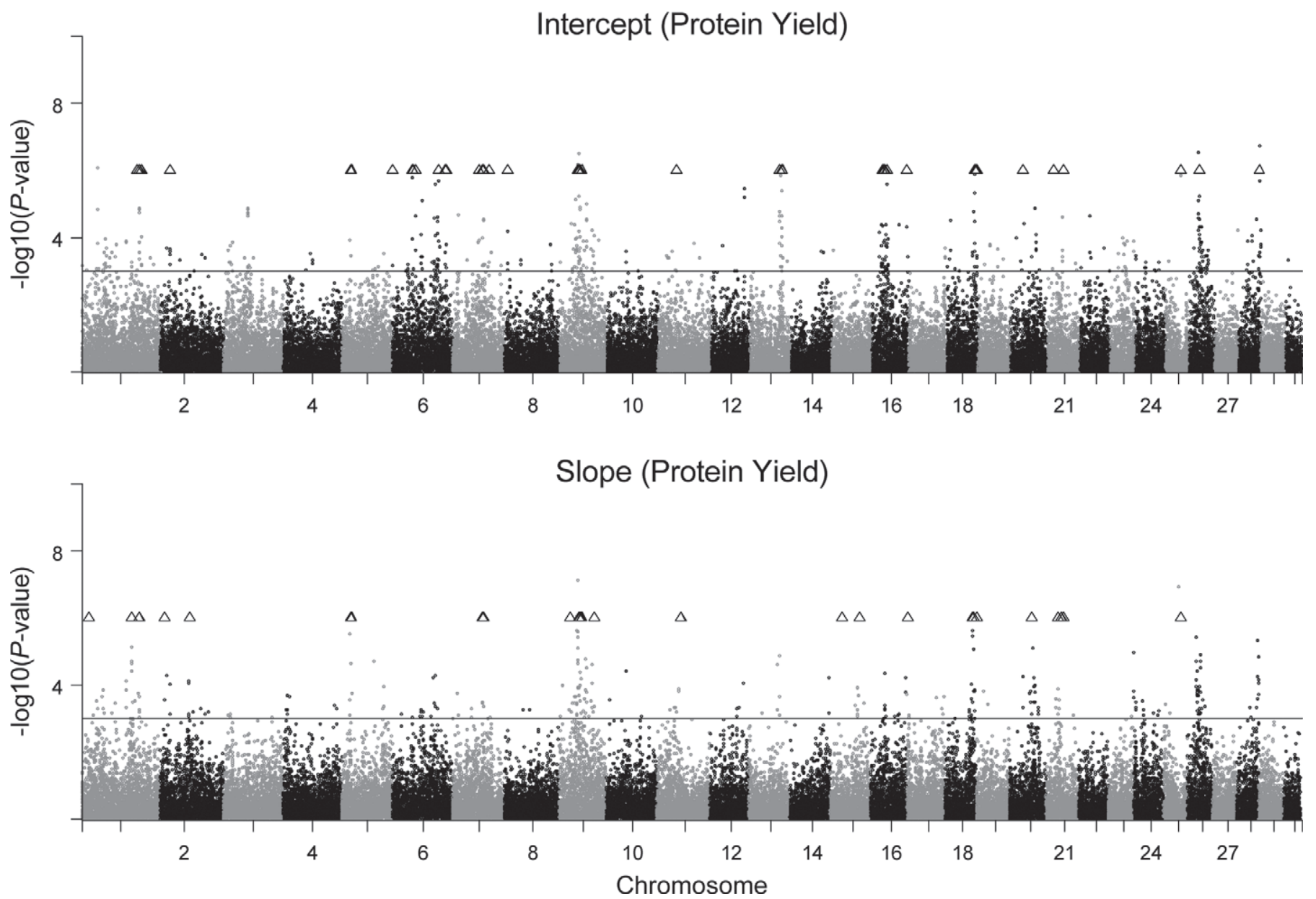

Figure 1. Test statistic profile of SNP effects for intercept and slope in the discovery data set. The nominal significance level $(P<0.001)$ is indicated by a solid line, and positions of validated SNP (less stringent validation) are indicated by triangles. The $-\log _{10}(P$-value) of SNP ARSBFGL-NGS-4939 on BTA14 was 12 for intercept (protein yield) and slope (protein yield) and is not shown in the figure. 
Table 2. Single nucleotide polymorphisms with a successful stringent validation $(P \leq 0.001$ in the validation set) for at least one trait with chromosome, position, $F$-values, and sign of the effect of the allele with the higher frequency for the traits

\begin{tabular}{|c|c|c|c|c|c|c|}
\hline \multirow{3}{*}{$\frac{\text { SNP }}{\text { ARS-BFGL-BAC-7205 }}$} & \multirow{3}{*}{$\frac{\mathrm{BTA}}{1}$} & \multirow{3}{*}{$\frac{\text { Position, bp }}{120983738}$} & \multicolumn{4}{|c|}{$F$-value $^{1}$ (sign of effect) } \\
\hline & & & \multicolumn{2}{|c|}{$\begin{array}{c}\text { Intercept } \\
\text { (protein yield) }\end{array}$} & \multicolumn{2}{|c|}{$\begin{array}{c}\text { Slope } \\
\text { (protein yield) }\end{array}$} \\
\hline & & & 19.03 & $(-)$ & 14.11 & $(+)$ \\
\hline ARS-BFGL-NGS-99492 & 1 & 121607486 & 18.91 & $(-)$ & 13.66 & $(+)$ \\
\hline BTA-114011-no-rs & 1 & 125911737 & 11.76 & $(+)$ & 1.48 & $(-)$ \\
\hline BTB-00056059 & 1 & 126163013 & 11.51 & $(-)$ & 3.27 & $(+)$ \\
\hline ARS-BFGL-NGS-68464 & 5 & 18395406 & 12.88 & $(-)$ & 18.06 & $(+)$ \\
\hline Hapmap33079-BTA-163567 & 6 & 1936 & 11.58 & $(+)$ & 6.07 & $(-)$ \\
\hline BTA-110673-no-rs & 6 & 111383112 & 11.36 & $(-)$ & 6.73 & $(+)$ \\
\hline BTB-00281303 & 6 & 111612203 & 14.34 & $(-)$ & 7.89 & $(+)$ \\
\hline ARS-BFGL-NGS-113181 & 7 & 62800839 & 15.09 & $(+)$ & 12.83 & $(-)$ \\
\hline ARS-BFGL-NGS-113819 & 7 & 63609102 & 17.37 & $(+)$ & 8.77 & $(-)$ \\
\hline ARS-BFGL-NGS-109819 & 7 & 63664393 & 17.65 & $(+)$ & 10.14 & $(-)$ \\
\hline BTB-01880776 & 7 & 64095706 & 11.68 & $(+)$ & 7.98 & $(-)$ \\
\hline ARS-BFGL-NGS-52530 & 9 & 44230587 & 24.26 & $(-)$ & 29.15 & $(+)$ \\
\hline BTB-00391835 & 9 & 52160813 & 11.14 & $(-)$ & 11.57 & $(+)$ \\
\hline ARS-BFGL-NGS-113322 & 11 & 38523074 & 8.07 & $(+)$ & 14.43 & $(-)$ \\
\hline BTA-93012-no-rs & 11 & 38544853 & 8.03 & $(+)$ & 14.66 & $(-)$ \\
\hline ARS-BFGL-NGS-63777 & 13 & 67075815 & 21.32 & $(+)$ & 11.37 & $(-)$ \\
\hline ARS-BFGL-NGS- $4939^{2}$ & 14 & 443936 & 78.92 & $(+)$ & 65.82 & $(-)$ \\
\hline ARS-BFGL-NGS-113877 & 16 & 29456497 & 12.24 & $(-)$ & 10.66 & $(+)$ \\
\hline Hapmap38953-BTA-38562 & 16 & 29487613 & 12.24 & $(-)$ & 10.66 & $(+)$ \\
\hline Hapmap50594-BTA-121054 & 16 & 29757246 & 11.34 & $(+)$ & 4.24 & $(-)$ \\
\hline ARS-BFGL-NGS-26559 & 16 & 33367687 & 14.47 & $(-)$ & 12.04 & $(+)$ \\
\hline ARS-BFGL-NGS-59645 & 16 & 73117625 & 16.58 & $(+)$ & 10.28 & $(-)$ \\
\hline BTB-02013769 & 16 & 74080339 & 5.84 & $(+)$ & 14.35 & $(-)$ \\
\hline ARS-BFGL-NGS-35499 & 18 & 50131636 & 5.47 & $(+)$ & 11.14 & $(-)$ \\
\hline ARS-BFGL-NGS-6001 & 21 & 25932661 & 7.83 & $(-)$ & 14.69 & $(+)$ \\
\hline Hapmap52867-rs29023496 & 21 & 26401500 & 7.02 & $(-)$ & 12.11 & $(+)$ \\
\hline ARS-BFGL-NGS-110044 & 21 & 30892171 & 12.64 & $(+)$ & 7.59 & $(-)$ \\
\hline ARS-BFGL-NGS-55374 & 25 & 28795160 & 23.44 & $(-)$ & 28.25 & $(+)$ \\
\hline
\end{tabular}

${ }^{1}$ Bold $F$-values indicate traits for which validation was successful.

${ }^{2}$ This SNP is in near complete linkage disequilibrium with the DGAT1 K232A substitution (Wang et al., 2012).

herd-test-day SCS levels. Compared with the intercept variance, the variance of the slopes was small. However, it is important to note that the slope variance depends on the range of the environmental values and a wider range yields a larger slope variance. In a previous study we found this variance, and therefore the presence of $\mathrm{G} \times \mathrm{E}$ with this environmental descriptor, to be highly significant (Streit et al., 2012). The correlation between intercept and slope depends on where the intersection point of the reaction norm model is placed. As recommended by Kolmodin and Bijma (2004), we placed it in the average environment. In this case, the intercept estimate can be interpreted as an estimate for average or general production and the slope as an estimate for the environmental sensitivity. The negative correlation between intercept and slope under this condition means that with a decrease in the average herd SCS level (i.e., in an "improved" environment), the genotype value increases. This trend was frequently observed with other environmental descriptors; for example, average herd milk production (Kolmodin et al., 2002; Lillehammer et al., 2009a). Hence, with an ongoing selection on general production, there will also be substantial correlated selection response for environmental sensitivity.

Many SNP were identified and confirmed that are involved in intercept and slope. Some interesting SNP or SNP clusters are located next to candidate genes for milk protein segregating in the Germans Holsteins; for example, on BTA6 (Kühn et al., 1999; Bennewitz et al., 2004a), BTA5, and BTA20 (Wang et al., 2012). Interestingly, no other SNP on BTA14 close to the one in near-complete linkage disequilibrium with DGAT1 K232A substitution was significantly associated with intercept and slope. Hence, this SNP explained the major QTL for milk traits frequently reported in this population (Thaller et al., 2003; Bennewitz et al., 2004b). The SNP significant solely for slope (Table 2) demonstrate the advantages of considering $\mathrm{G} \times \mathrm{E}$. For these SNP, the allele that is superior in one half of the environment is inferior in the second half and both alleles show a similar effect in the average environment and, hence, they are not significant for intercept. 
Many SNP affecting slope in this study also affected slope when average herd milk production was used as environment (Streit et al., 2013), although the correlation between 2 environmental descriptors was low and slightly negative. The signs of the effects were almost always such that the effect of the SNP increased in an "improved" environment (higher average milk production or lower SCS, Table 2; Streit et al., 2013). Hence, for robustness breeding purposes for both a fluctuating milk production environment and a fluctuating SCS environment, a similar set of SNP is important. Exceptions are the SNP on BTA11, 16, 18, and 21 that were significant for slope but not for intercept (Table 2 ). These were not significant for slope in our previous study, where the environment was modeled as the average herd milk production (Streit et al., 2013). Hence, these SNP are not involved in general production and are environment sensitive only to the SCS environment.

Lillehammer et al. (2009a) discussed the use of intercept and slope SNP for breeding of robust animals. They suggested considering SNP with effects for intercept and slope in opposite directions; that is, SNP with a smaller effect in an improved environment, because these SNP are not in line with the polygenic correlation between intercept and slope. This class of SNP was not identified in this study. Therefore, if robustness for milk traits in a fluctuating SCS environment is desired, single-marker-assisted selection cannot be recommended. Instead, genomic selection considering important SNP simultaneously seems to be more promising.

Several environmental descriptors have been used in reaction norm models in dairy cattle (Fikse et al., 2003; Strandberg et al., 2009). In this study, average herd SCS levels obtained from routine genetic animal evaluations were used as an indicator trait for udder health and hygiene conditions on the farms at the time where the trait yield was recorded. Herd-test-day observations were used, which offered the possibility to also capture the within-cow variance (Hayes et al., 2003). Indeed, daughter variance was substantial. It modeled the additive genetic variance not included in the sire effects and some within-cow variability. In addition, it was possible to use the variance of the environmental descriptor within herd among the test days. This might be especially useful for the average herd-test-day SCS environmental descriptor, because it can be expected that the SCS fluctuation within herds is larger compared with milk traits; for example, due to temporary herd mastitis infections. Mastitis can be due to different classes of pathogens - environmental pathogens such as Escherichia coli or contagious pathogens such as Streptococcus agalactiae and Staphylococcus aureus. Mastitis caused by environmental pathogens generally results in a lower SCC than that caused by contagious pathogens (Barkema et al., 1998). Hence, average herd SCS level as a proxy to describe the herd level of udder health and hygiene has limits.

\section{CONCLUSIONS}

Genotype by environment interactions for protein yield and average herd SCS as environmental descriptors were detected using a first-order sire reaction norm model. Many SNP or SNP clusters were identified that affected intercept and slope of the reaction norm. The number of SNP affecting intercept was larger, and some significant SNP affected only slope. Considering $\mathrm{G} \times \mathrm{E}$ improved the statistical power to map SNP involved in protein yield variation. A comparison with an earlier study revealed that SNP affecting slope were generally also significant for slope when the environment was modeled by the average herd milk production level, although both environmental descriptors were poorly correlated. In future studies, it might be of interest to fit both environments simultaneously to the models. In addition, an across-breed analysis in combination with a higher marker density is desired to validate the effects in another population and to fine-map the underlying causal mutation.

\section{ACKNOWLEDGMENTS}

M. Streit was supported by a grant from the Deutsche Forschungsgemeinschaft (Germany).

\section{REFERENCES}

Barkema, H. W., Y. H. Schukken, T. J. G. M. Lam, M. L. Beiboer, H. Wilmink, G. Benedictus, and A. Brand. 1998. Incidence of clinical mastitis in dairy herds grouped in three categories by bulk milk somatic cell counts. J. Dairy Sci. 81:411-419.

Barkema, H. W., J. D. van der Ploeg, Y. H. Schukken, T. J. G. M. Lam, G. Benedictus, and A. Brand. 1999. Management style and its associations with bulk milk somatic cell count and incidence rate of clinical mastitis. J. Dairy Sci. 82:1655-1663.

Bennewitz, J., N. Reinsch, V. Guiard, S. Fritz, H. Thomsen, C. Looft, C. Kühn, M. Schwerin, C. Weimann, G. Erhardt, F. Reinhardt, R. Reents, D. Boichard, and E. Kalm. 2004a. Multiple quantitative trait loci mapping with cofactors and application of alternative variants of the false discovery rate in an enlarged granddaughter design. Genetics 168:1019-1027.

Bennewitz, J., N. Reinsch, S. Paul, C. Looft, B. Kaupe, C. Weimann, G. Erhardt, G. Thaller, C. Kühn, M. Schwerin, H. Thomsen, F. Reinhardt, R. Reents, and E. Kalm. 2004b. The DGAT1 K232A mutation is not solely responsible for the milk production quantitative trait locus on the bovine chromosome 14. J. Dairy Sci. 87:431-442.

Dufour, S., A. Fréchette, H. W. Barkema, A. Mussell, and D. T. Scholl. 2011. Invited review: Effect of udder health management practices on herd somatic cell count. J. Dairy Sci. 94:563-579. http://dx.doi.org/10.3168/jds.2010-3715.

Fikse, W. F., R. Rekaya, and K. A. Weigel. 2003. Assessment of environmental descriptors for studying genotype by environment interaction. Livest. Prod. Sci. 82:223-231. http://dx.doi.org/10.1016/ S0301-6226(03)00009-5. 
Gilmour, A. R., B. J. Gogel, B. R. Cullis, and R. Thompson. 2009. ASReml User Guide 3.0. VSN International Ltd., Hemel Hempstead, UK.

Hayes, B. J., P. J. Bowman, A. J. Chamberlain, K. Savin, C. P. van Tassell, T. S. Sonstegard, and M. E. Goddard. 2009. A validated genome wide association study to breed cattle adapted to an environment altered by climate change. PLoS ONE 4:e6676.

Hayes, B. J., M. Carrick, P. Bowman, and M. E. Goddard. 2003. Genotype $\times$ environment interaction for milk production of daughters of Australian dairy sires from test-day records. J. Dairy Sci. $86: 3736-3744$.

Kolmodin, R., and P. Bijma. 2004. Response to mass selection when the genotype by environment interaction is modelled as a linear reaction norm. Genet. Sel. Evol. 36:435-454.

Kolmodin, R., E. Strandberg, P. Madsen, J. Jensen, and H. Jorjani. 2002. Genotype by environment interaction in Nordic dairy cattle studied using reaction norms. Acta Agric. Scand. A Anim. Sci. $52: 11-24$.

König, S., G. Dietl, I. Raeder, and H. H. Swalve. 2005. Genetic relationships for dairy performance between large-scale and smallscale farm conditions. J. Dairy Sci. 88:4087-4096.

Kühn, C., G. Freyer, R. Weikard, T. Goldammer, and M. Schwerin. 1999. Detection of QTL for milk production traits in cattle by application of a specifically developed marker map of BTA6. Anim. Genet. 30:333-340.

Lillehammer, M., B. J. Hayes, T. H. E. Meuwissen, and M. E. Goddard. 2009a. Gene by environment interactions for production traits in Australian dairy cattle. J. Dairy Sci. 92:4008-4017.

Lillehammer, M., J. Ødegård, and T. H. E. Meuwissen. 2009b. Reducing the bias of estimates of genotype by environment interactions in random regression sire models. Genet. Sel. Evol. 41:30.

Lynch, M., and B. Walsh. 1998. Genetics and Analysis of Quantitative Traits. Sinauer Associates Inc. Publishers, Sunderland, MA.

Matukumalli, L. K., C. T. Lawley, R. D. Schnabel, J. F. Taylor, M. F. Allan, M. P. Heaton, J. O'Connell, S. S. Moore, T. P. L. Smith, T. S. Sonstegard, and C. P. van Tassell. 2009. Development and characterization of a high density SNP genotyping assay for cattle. PLoS ONE 4:e5350.

Pryce, J. E., S. Bolormaa, A. J. Chamberlain, P. J. Bowman, K. Savin, M. E. Goddard, and B. J. Hayes. 2010. A validated genome-wide association study in 2 dairy cattle breeds for milk production and fertility traits using variable length haplotypes. J. Dairy Sci. 93:3331-3345. http://dx.doi.org/10.3168/jds.2009-2893.

Purcell, S., B. Neale, K. Todd-Brown, L. Thomas, M. A. R. Ferreira, D. Bender, J. Maller, P. Sklar, P. I. W. de Bakker, M. J. Daly, and P. C. Sham. 2007. PLINK: A tool set for whole-genome association and population-based linkage analyses. Am. J. Hum. Genet. 81:559-575.

Qanbari, S., E. C. G. Pimentel, J. Tetens, G. Thaller, P. Lichtner, A. R. Sharifi, and H. Simianer. 2010. The pattern of linkage disequilibrium in German Holstein cattle. Anim. Genet. 41:346-356.

Scheet, P., and M. Stephens. 2006. A fast and flexible statistical model for large-scale population genotype data: Applications to inferring missing genotypes and haplotypic phase. Am. J. Hum. Genet. 78:629-644.

Storey, J. D., and R. Tibshirani. 2003. Statistical significance for genomewide studies. Proc. Natl. Acad. Sci. USA 100:9440-9445.

Strandberg, E., S. Brotherstone, E. Wall, and M. P. Coffey. 2009. Genotype by environment interaction for first-lactation female fertility traits in UK dairy cattle. J. Dairy Sci. 92:3437-3446. http:// dx.doi.org/10.3168/jds.2008-1844.

Streit, M., F. Reinhardt, G. Thaller, and J. Bennewitz. 2012. Reaction norms and genotype-by-environment interaction in the German Holstein dairy cattle. J. Anim. Breed. Genet. 129:380-389. http://dx.doi.org/10.1111/j.1439-0388.2012.00999.x.

Streit, M., R. Wellmann, F. Reindardt, G. Thaller, H. P. Piepho, and J. Bennewitz. 2013. Using genome-wide association analysis to characterize environmental sensitivity of milk traits in dairy cattle. G3 (Bethesda) 3:1085-1093. http://dx.doi.org/10.1534/ g3.113.006536.

Thaller, G., W. Krämer, A. Winter, B. Kaupe, G. Erhardt, and R. Fries. 2003. Effects of DGAT1 variants on milk production traits in German cattle breeds. J. Anim. Sci. 81:1911-1918.

Veerkamp, R. F., H. A. Mulder, M. P. L. Calus, J. J. Windig, and J. ten Napel. 2009. Statistical genetics to improve robustness of dairy cows. Proc. Assoc. Adv. Anim. Breed. Genet. 18:406-413.

Wang, X., C. Wurmser, H. Pausch, S. Jung, F. Reindardt, J. Tetens, G. Thaller, and R. Fries. 2012. Identification and dissection of four major QTL affecting milk fat content in the German HolsteinFriesian population. PLoS ONE 7:e40711. 